\title{
Comparison of Classic Discriminant Analysis and Two-state Logistic Regression in Separation of Sardasht City, Iran, Chemical Victims to Mustard Gas Exposed and Non-Exposed Groups
}

\section{ART ICLE INF O}

\section{Article Type}

Descriptive Study

\section{Authors}

Bigdeli Z. ${ }^{1} M S C$,

Ghazanfari T. ${ }^{2} P h D$,

Naghizadeh M.M. ${ }^{3} M S c$,

Nasiri M. ${ }^{4} P h D$

Faghihzadeh S. ${ }^{* 1} \mathrm{PhD}$

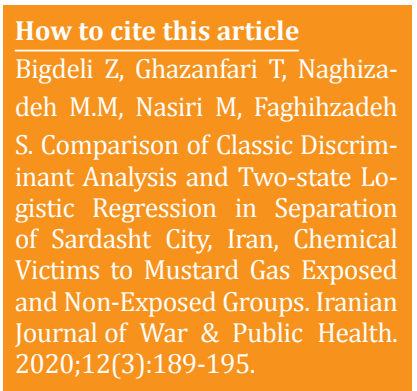

${ }^{1}$ Department of Biostatistics, School of Medicine, Zanjan University of Medical Sciences, Zanjan, Iran ${ }^{2}$ Safety Response Regulation Research Center, Shahed University, Tehran, Iran

${ }^{3}$ Non-Communicable Diseases Research Center, Fasa University of Medical Sciences, Fars, Iran

${ }^{4}$ Department of Biostatistics, Faculty of Nursing, Shahid Beheshti University, Tehran, Iran

\section{*Correspondence}

Address: Department of Biostatistics, School of Medicine, Zanjan University of Medical Sciences, Mahdavi Street, Zanjan, Iran. Postal Code: 4513956111.

Phone: +98 (24) 33140152

Fax: +98 (24) 33449553

s.faghihzadeh@gmail.com

\section{Article History}

Received: February 04, 2020

Accepted: September 28, 2020

ePublished: March 03, 2021

\section{A B S T R A C T}

Aims The aim of this study was to separate the chemical victims of mustard gas into exposed to and non-exposed groups to sulfur mustard using classical discriminant analysis and twostate logistic regression and selection of the best analysis.

Instruments \& Methods The present study is a historical group that was conducted from 2005 to 2014. By observation method and systematic sampling, 284 people were included in the study including 216 people from Sardasht City as an exposed group and 68 people from Rabat City as a control group who were in all respects compared to the case group. Using classical discriminant analysis and logistic regression methods, 32 quantitative variables were examined and finally these two methods were compared using rock curve analysis. SPSS 21 software was used for analysis.

Findings The 8 significant variables that had the highest ability to differentiate the groups (FEV1/FVC ratio, testosterone, cholesterol, phosphorus, conjugated bilirubin, red blood cell count, hemoglobin and hematocrit) were selected and entered into the main models. Using the rock curve, the cutting points of the variables were determined and the sensitivity and specificity values for discriminant analysis were $78 \%$ and $77.5 \%$, respectively, and its sub-curved surface was $81.2 \%$. In differentiating the groups, testosterone index was the strongest variable and conjugated bilirubin factor was the weakest variable. In logistic regression model, FEV1/FVC, testosterone and phosphorus ratio variables were significant $(\mathrm{p}<0.05)$. The sensitivity and specificity of this model were $80 \%$ and $75 \%$, respectively, the rock curvature level was $81.4 \%$ and the value of $\mathrm{R}^{\wedge} 2$ was 0.308 .

Conclusion In the separation of chemical victims, the classical discriminant analysis and logistic regression methods have similar results, but discriminant analysis is a more appropriate model due to the presentation of the diagnostic function.

Keywords Discriminant Analysis; Detection Function; Rock Curve; Logistic Regression; Chemical Victims; Iran

\section{I T A T I O N L I N K S}

[1] A Review of the late effects of sulfur mustard gas ... [2] Toxicodynamics of sulfur ... [3] Comparison of early and late toxic effects of sulfur mustard ... [4] Lethal intoxication by wargases ... [5] Observation and clinical manifestation of patient ... [6] Studies on DNA repair in early spermatid stages of male mice after in vivo treatment with methyl- , ethyl ... [7] Late manifestations in former mustard gas workers with special ... [8] Concentration of mustard gas [Bis(2-chloroethylin) ... [9] The clinical toxicology of sulfur mustard ... [10] Sardasht-Iran cohort study of chemical warfare ... [11] Fitting logistic model to some quantitative and qualitative variables to discriminate between ... [12] Studying the surrogate validity of respiratory indexes in predicting the respiratory illnesses in ... [13] Quality of life in chemical warfare survivors with ophthalmologic injuries: The first results from Iran chemical ... [14] Comparison of logistic regression and discriminant ... [15] Logistic regression and linear discriminant analyses in evaluating factors associated with asthma prevalence among ... [16] The use of discriminant analysis, logistic regression ... [17] Longitudinal discriminant analysis with random effects ... [18] Comparison of artifitial neural network, logistic regression ... [19] Choosing between logistic regression and discriminant ... [20] Linear discriminant analysis-a brief ... [21] Comparison of logistic regression and neural network ... [22] Comparison of artificial neural network models with logistic ... [23] Evaluation of serum and sputum level of il-21 in sardasht ... 


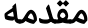
استفاده گستره از خردل گوگردى در قرن گذشته، اثرات سمى

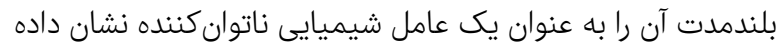

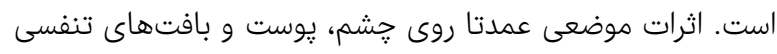

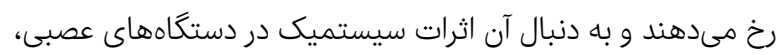

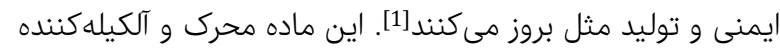

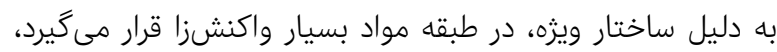

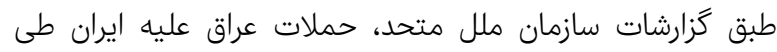

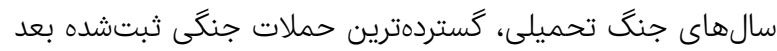

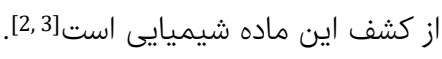

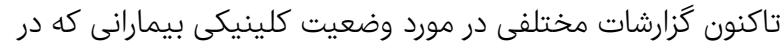

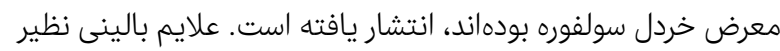

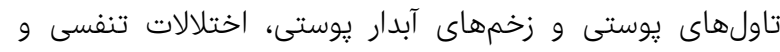

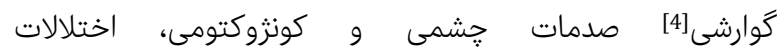

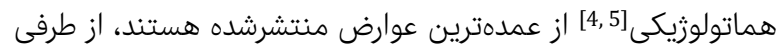

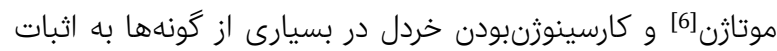

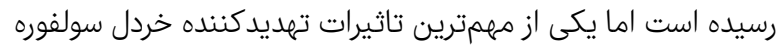

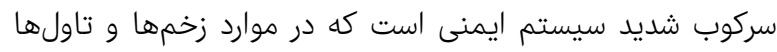

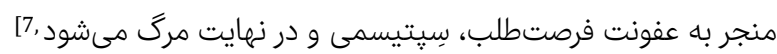
[8. خردل گوگردى سبب تغيير ماهيت اسيدهاى نوكلئيك و و يروتئينها و باعث برهمخوردن هموستاز و در نهايت مرى سلو سلول

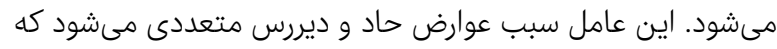

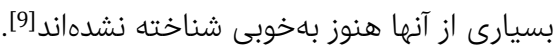

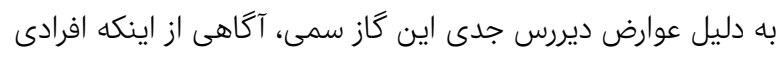

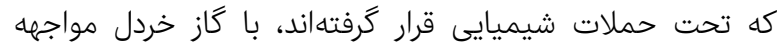

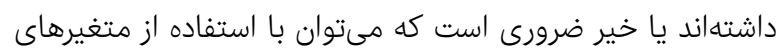

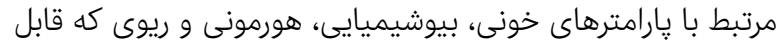

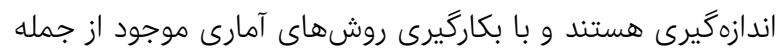

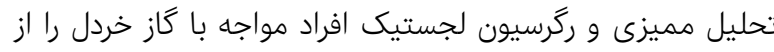

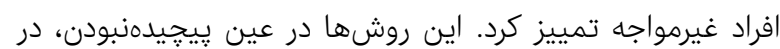
علوم يزشكى بسيار مفيد و كاربردى نيز هستند.

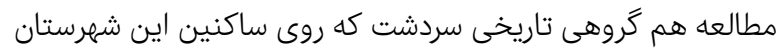

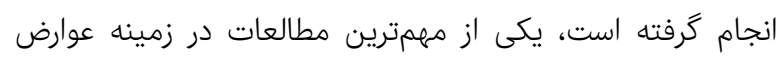

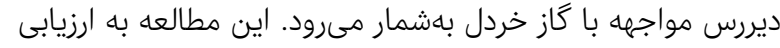

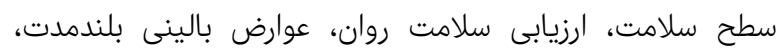

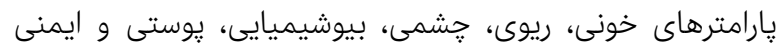

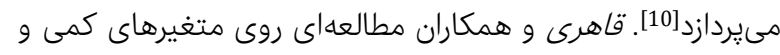
كيفى كوهورت تاريخى سردشت، با روش رگرسيون لجستيك انجام

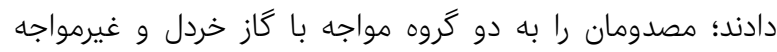

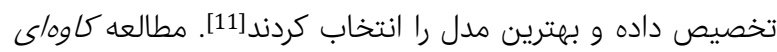

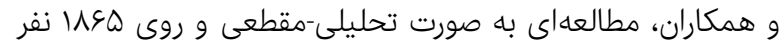

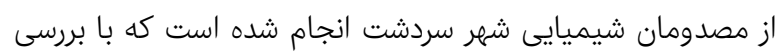

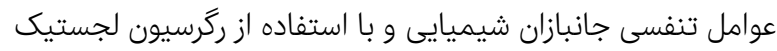

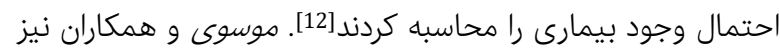

مقايسه تحليل مميزى كلاسيك و و ركرسيون لجستيك دو حالتى در تفكيك مصدومان شيميايى شهرستان سردشت به گروههاى مواجه و غيرمواجه

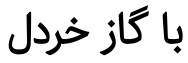

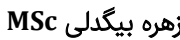

كروه آمار زيستى، دانشكده يزشكى، دانشكاه علوم يزشكى زنجان، زنجان، ايران

PhD Pوبى غضنفرى

مركز تحقيقات تنظيم پاسخهاى ايمنى، دانشكاه شاهد، تهران، ايران

MSc محمدمهدى نقىزاديه

مركز تحقيقات بيمارىهاى غيراده غيرواگير، دانشكاه علوم يزشكى فسا، فارس، ايران

مليحه نصيرى PhD

كروه آمار زيستى، دانشكده برستارى، دانشكاه شهيد بهشتى، تهران، ايران

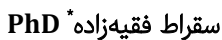

كروه آمار زيستى، دانشكده يُشكى، دانشكاه علوم يزّكى زنجان، زنجان، ايران

جكيده

اهداف: اين مطالعه با هدف تفكيك مصدومان شيميايى كَاز خردل به كروههاى

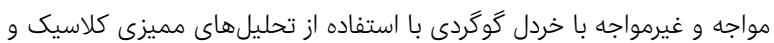

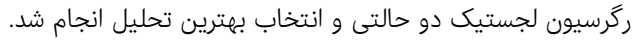

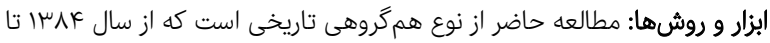

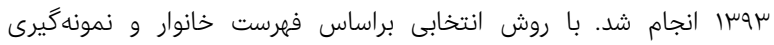

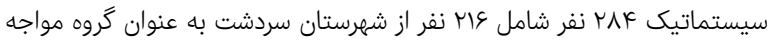

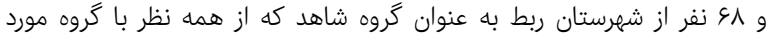

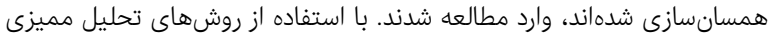

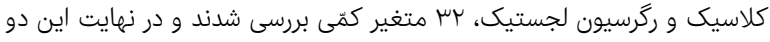

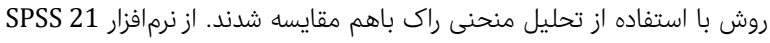
براى تجزيه و تحليل استفاده شد. يافتهها: ^ متغير معنىدار كه بيشترين توانايى را در تفكيك گرومها داشتنداد

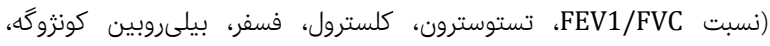

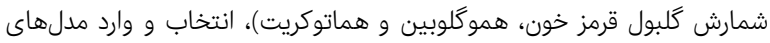

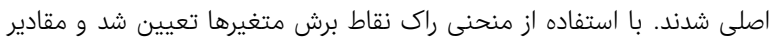

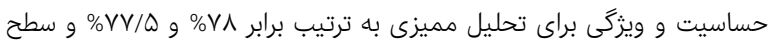

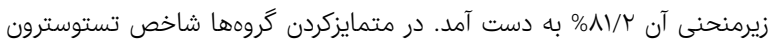

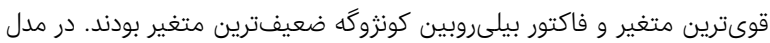

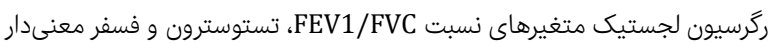

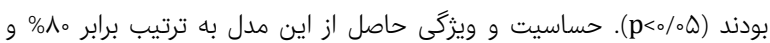

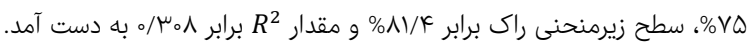

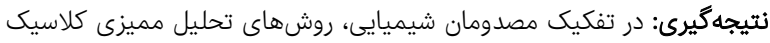

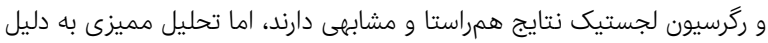

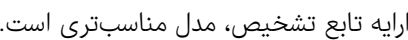

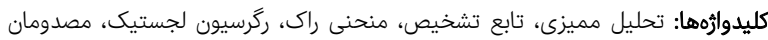

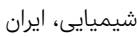

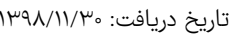

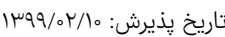

نويسنده مسئول: s.faghihzadeh@gmail.com 


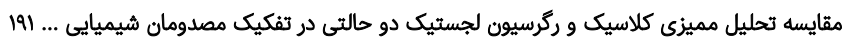

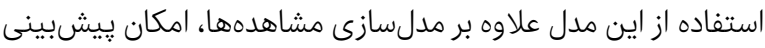

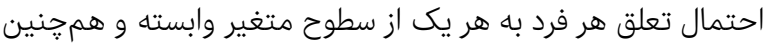

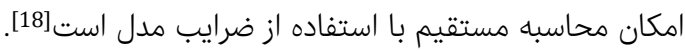

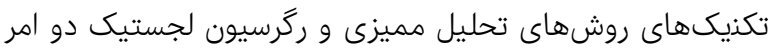

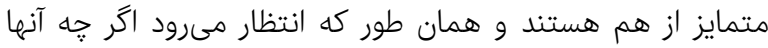

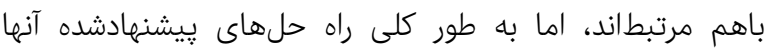

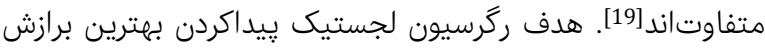

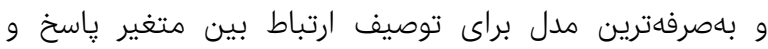
مجموعهاى از متغيرهاى مستقل (ييشبينىكنينده يا توضيحى)

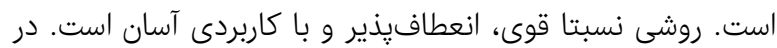
ركرسيون لجستيك برخلاف تحليل مميزى خطى هيج فرضيهنيه أنطافيى

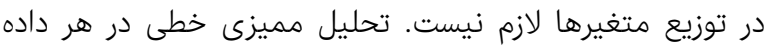

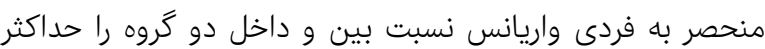
مىكند. به اين صورت تفكيكيذيرى حداكثرى تضمين مى شود

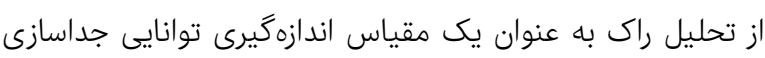
يك مدل استفاده مىشود كه بيشترين ناحيه زيرمنهنى نشاندهنده توانايى ييشبينى بهتر براى مقايسه مدلهادهاست. درد

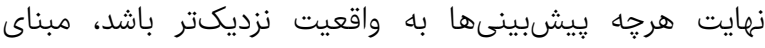

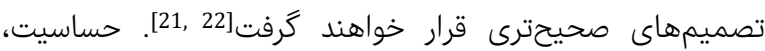

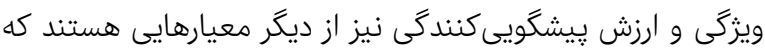

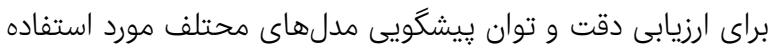

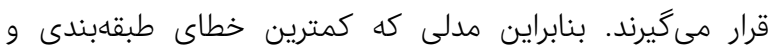

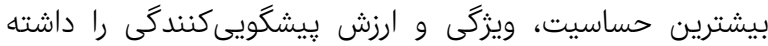

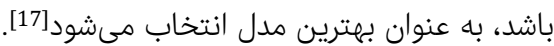

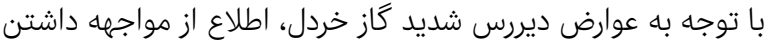

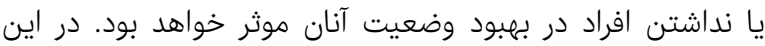
مطالعه هدف اين بود كه با استفاده از برخى متغيرهاى كمّى مانند

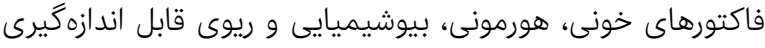

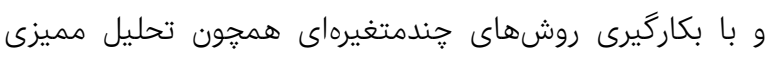
كلاسيك و رگرسيون لجستيك دو حالتى به برآورد احتمال حضور

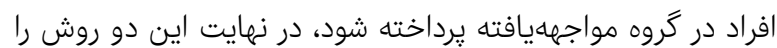
مقايسه كرده و بهترين مدل انتخاب شود.

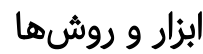

مطالعه حاضر از نوع همگروهى تاريخى است و روى بAk نفر از

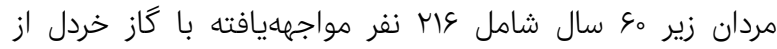

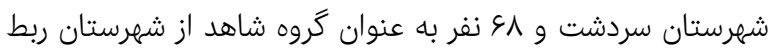
انجام شد. گروه مواجهانيافته شامل مردانى بود كه به به روست روش نمونه گيرى تصادفى ساده از روى آخرين ليست كروه آمار سرشمارى

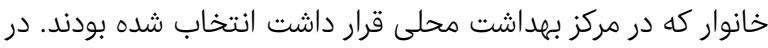

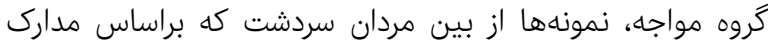

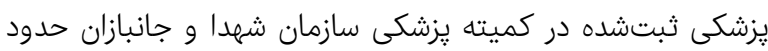

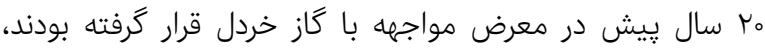

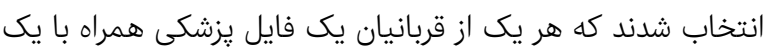

مطالعهاى به روش ركرسيون لجستيك انجام داده و متغيرهاى

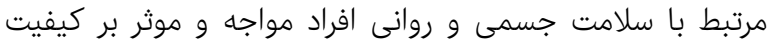
زندگى اين افراد را مشخص كردند [13].

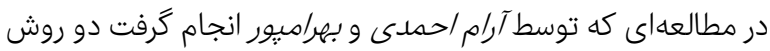

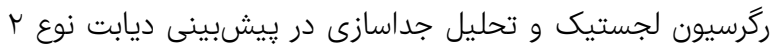

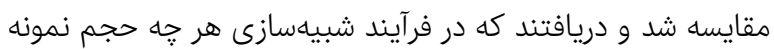
بزرگ باشد، نتايج مدلهاى رگرسيون لجستيك و تحليل جدئن جداسازى به هم نزديكتر خواهد بود [14]. در مطالعهاى كه توسط آنتونوجورجس و همكاران انجام شده است، دو مدل رگرسيون لجستيك و تحليل مميزى خطى را براى ارزيابى

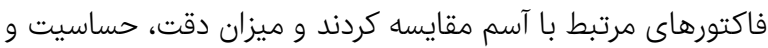

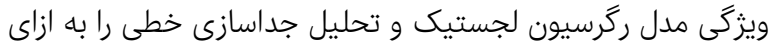
نقطه برشهاى مختلف به دست آوردند و درنهايت به ايه اين نتيجها رسيدند كه به طور كلى، تابع جداسازى خطى زمانى كه فرضيههاى

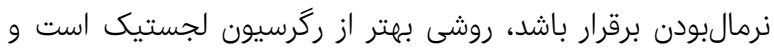

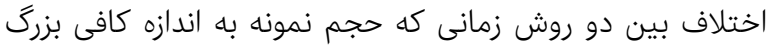

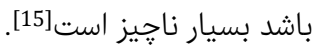
يكى از موضوعات مطرح در مطالعات يزشكى اين است كه برخى

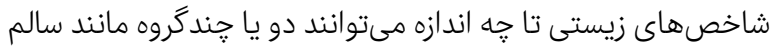

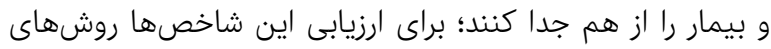

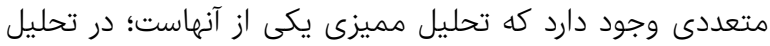

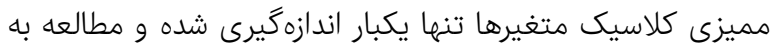

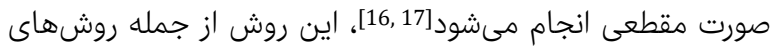

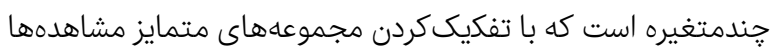

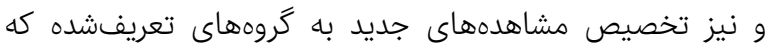

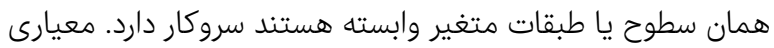

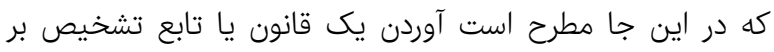

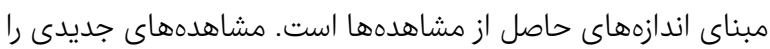

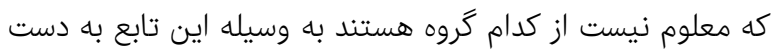

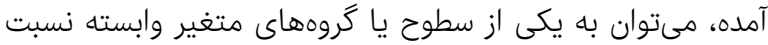

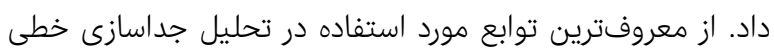

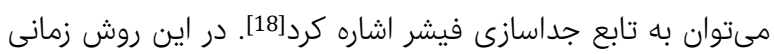

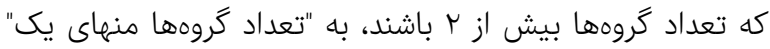

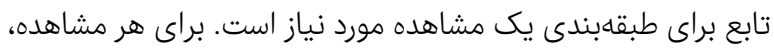

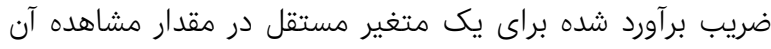

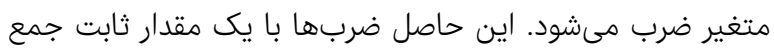

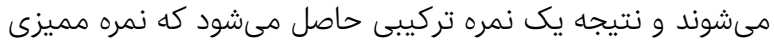

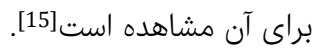
ركرسيون لجستيك فرمى از رگرسيون است، زمانى مورد استفاده قرار

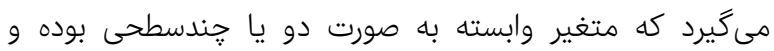

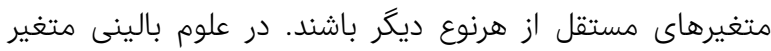

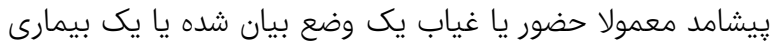

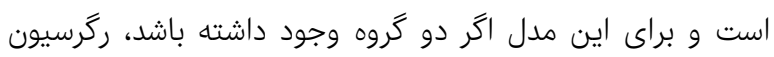

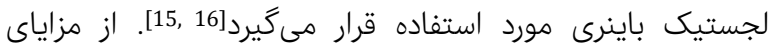


البته FEV1 به دليل همبستگى بالا با FEV1/FVC از تحليلها

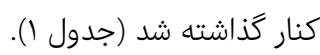

جدول () نتايج ميانكين متغيرهاى تمييزدهنده و معنادارى آنها با آزمون

مستقل

\begin{tabular}{|c|c|c|c|}
\hline p-value & غيرمواجه & مواجه & متغير \\
\hline \%०० & $110 / 90 \pm 1 \varepsilon / 01$ & $1 . \Psi / \wedge \varepsilon \pm 17 / V \varepsilon$ & FEV1/FVC نسبت \\
\hline$<0 / 001$ & $0 / 91 \pm 1 / 17$ & $0 / 17 \pm 1 / \circ V$ & تستوسترون \\
\hline$\% 1$ & $1 \wedge \vee / \Lambda \Lambda \pm \mu T / / T$ & $191 / V 0 \pm \mu Y / Q Y$ & كلسترول \\
\hline$\% \mu$ & $\mathrm{T} / \wedge \pm \pm_{\circ} / 70$ & $0 / 91 \pm 0 / \wedge \varepsilon$ & فسفر \\
\hline$\% \varepsilon$ & 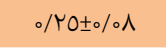 & $0 / \Upsilon Y \pm 0 / 0 \Lambda$ & بيلىروبين كونثروكه \\
\hline$\% \mu$ & $\varepsilon / 9 Y \pm 0 / \varepsilon\rceil$ & $0 / 0 \varepsilon \pm 0 / \varepsilon_{0}$ & شمارش كلبول قرمز خون \\
\hline$<0 / 001$ & $1 \varepsilon / 7 r \pm 1 / r o$ & $10 / \mu \mid \pm 1 / 1 \mu$ & هموكلوبين \\
\hline$<0 / 001$ & $\varepsilon 1 / \wedge q \pm \mu / \mu r$ & $\{\mu / \curlyvee \wedge \pm \mu / \circ\rceil$ & هماتوكريت \\
\hline
\end{tabular}

منحنىهاى راك براى هر كدام از مدلهاى تحليل مميزى كلاسيك

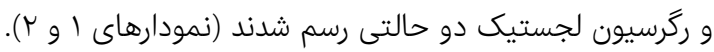

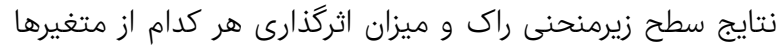
در تحليل مميزى كلاسيك در جدول r نشان دادئ داده شد.

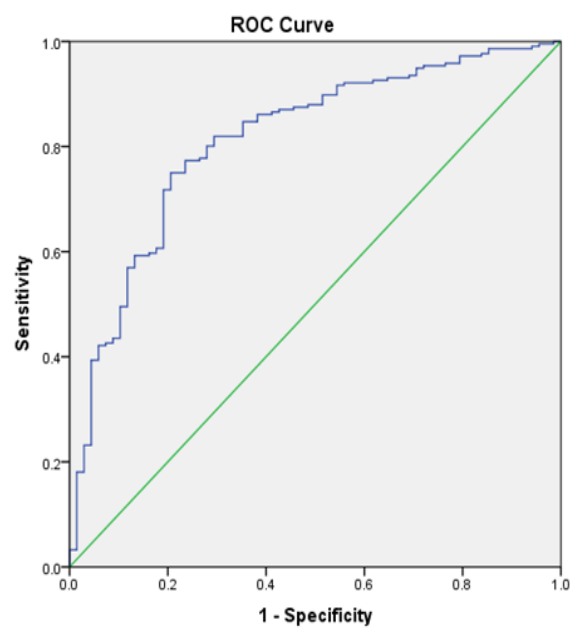

نمودار () منحنى راك براى مدل تحليل مميزى كلاسيك

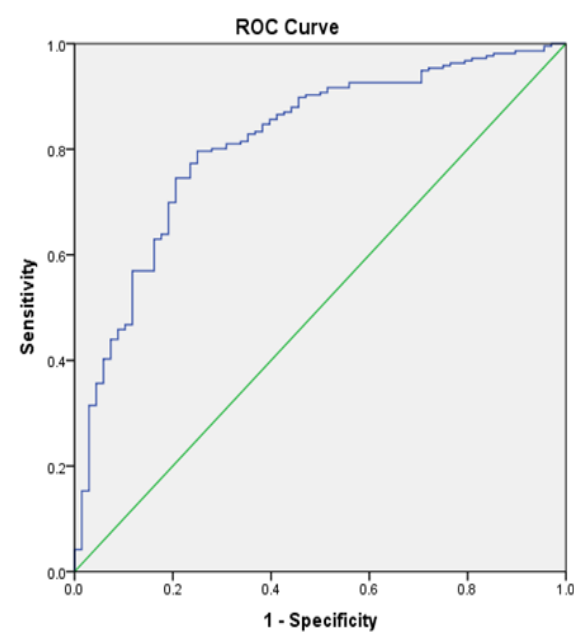

نمودار r) منحنى راك براى مدل رگرسيون لجستيك دو حالتى
كد عددى داشتند. از آنجا كه نسبت تعدار تهداد نمونه به تعداد ثبتشههها

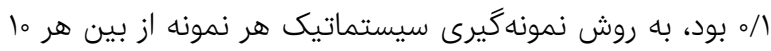

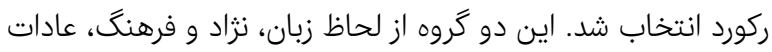

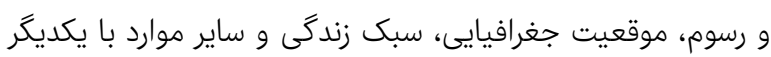

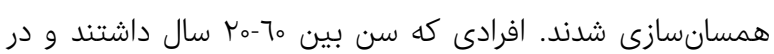

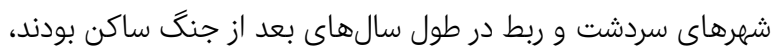

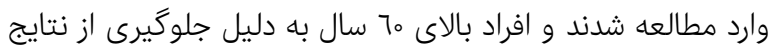
نامربوط ناشى از كاهش عملكرد سيستم ايمنى در افراد مسن، از از مطالعه خارج شدند [10].

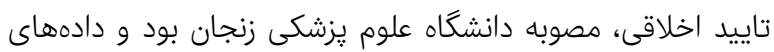

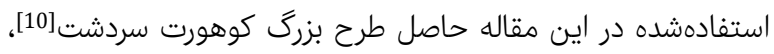

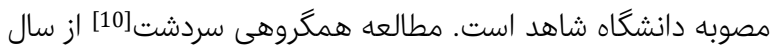

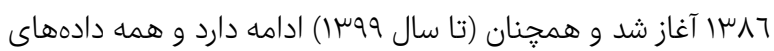
مطالعه حاضر، متغيرهاى مورد مطالعه، روش و ابزار و غيره برگرفته

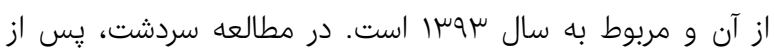
بررسى يِيشينه يزشكى افراد، قربانيان شيميايى براساس شدات

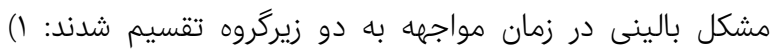

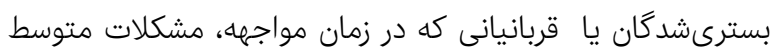

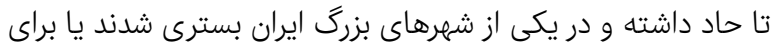

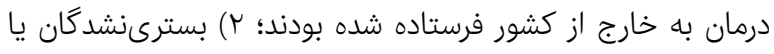
بيمارانى كه در زمان مواجهه، مشكلات خفيف يا شبهابالينى داشتند و براى اثرات بحرانى در بخش سريايى تحت درمان قرار گرَفته بودند.

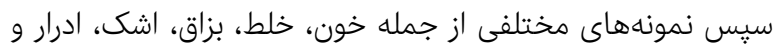

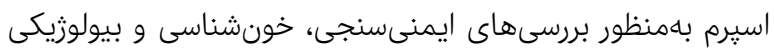

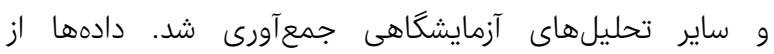

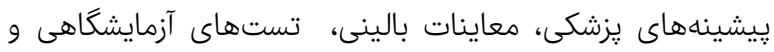

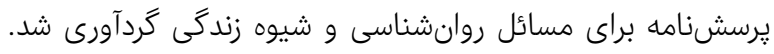

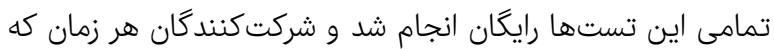

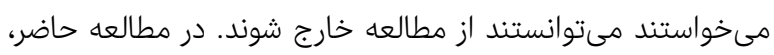

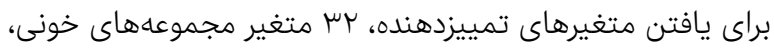

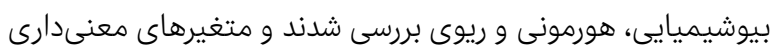

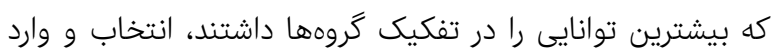

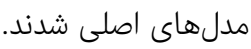

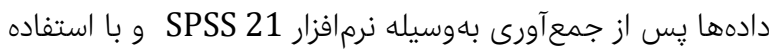

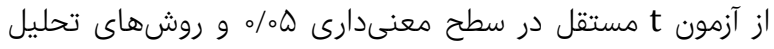

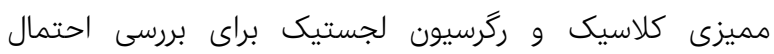

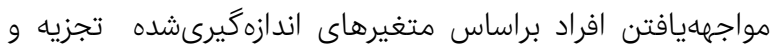
تحليل شدند.

\section{يافتهها}

از بين بس متغير بررسىشده، م متغير معنىدار كه بيشترين توانايى

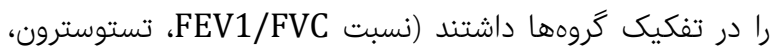
كلسترول، فسفر، بيلىروبين كونثروًه، شمارش كلبول قرمز خون،

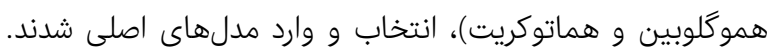


مقايسه تحليل مميزى كلاسيك و رگرسيون لجستيك دو حالتى در تفكيك مصدومان شيميايى ... سر19

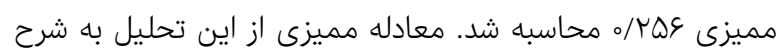
زير به دست آمد:

$\mathrm{D}=5.63+\left(.016 X_{1}\right)+\left(.649 X_{2}\right)+\left(-.007 X_{3}\right)+(-$

$\left..905 X_{4}\right)+\left(4.57 X_{5}\right)+$

$\left(-.018 X_{6}\right)+\left(-.452 X_{7}\right)+\left(-.018 X_{8}\right)$

ميزان تخصيص درست و غلط به دست آمد و از نتايج بهدست آمده

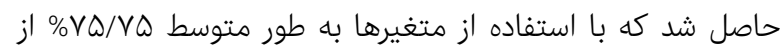

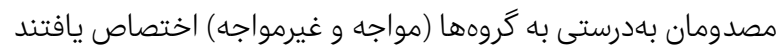

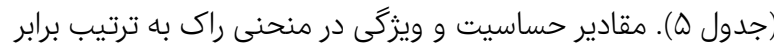

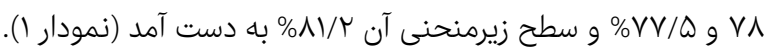

جدول ه) نتايج طبقابندى گروههاى مواجه و غيرمواجه

\begin{tabular}{|c|c|c|c|}
\hline درصد انطباق & نتيجه روش & برآورد اوليه & كروه \\
\hline$V \omega$ & 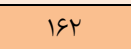 & MIS & مواجه با خردل گوگردى \\
\hline$V \& / Q$ & $\Delta r$ & $8 \Lambda$ & غيرمواجه با خردل گوگردى \\
\hline
\end{tabular}

مدل ركرسيون لجستيك با 1 متغير مذكور برازش داده شد (جدول

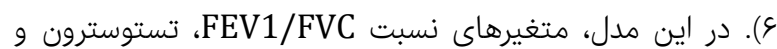

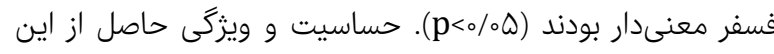

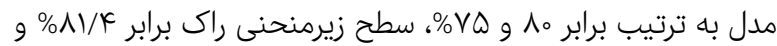

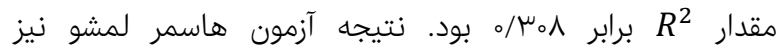

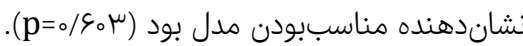

جدول \&) نتايج مدل رگرسيون لجستيك با حضور 1 متغير كمّى

\begin{tabular}{|c|c|c|c|c|}
\hline $\begin{array}{c}\text { p- } \\
\text { value }\end{array}$ & نسبت شانس & انحراف معيار & ضريب & متغير \\
\hline$\% F Q$ & ०/१VQ & \% & $-\circ / \sim_{\Delta}$ & نسبت FEV1/FVC \\
\hline$<0 / 001$ & o/krr & -/VVA & $-\circ / \wedge \uparrow 。$ & تستوسترون \\
\hline$\circ / 109$ & $1 / 00 V$ & $\% \circ \Delta$ & $\% \circ Y$ & كلسترول \\
\hline$\%$ o & $\mu / \circ \Delta q$ & $\circ / 49 \Delta$ & $1 / 111$ & فسفر \\
\hline$\circ / 11$ & $\circ \%$ & r/T\&A & $-\Delta / V V V$ & بيلىروبين كونثرگه \\
\hline ॰/9QH & I/TKq &.$/ 490$ & D/TYK & شمارش كلبول قرمز خون \\
\hline.$/ \mu \wedge q$ & $1 / 719$ & o/GrA & - /QFY & هموكلوبين \\
\hline ०/qY६ & ०/994 & D/TKq & $-\circ / \circ \wedge$ & هماتوكريت \\
\hline
\end{tabular}

بحث

اين مطالعه، مصدومان شيميايى را به وسيله متغيرهاى كمّى قابل

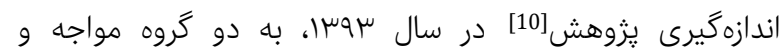
غيرمواجه تفكيك كرد. بنابر نتايج براى همه متغيرهاى معنى دردار

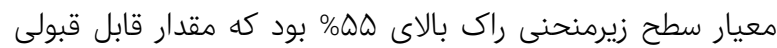

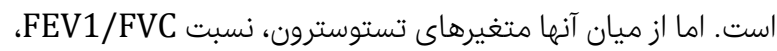

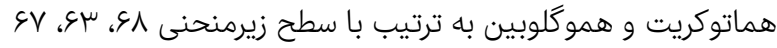

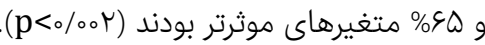

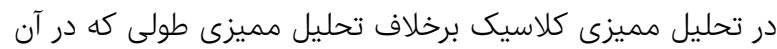

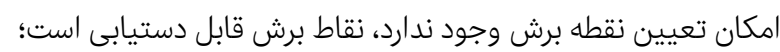

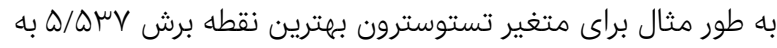

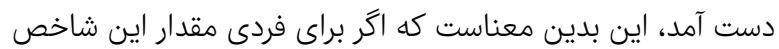

جدول r) سطح زيرمنحنى راك در تحليل مميزى كلاسيك (برحسب درصد)

\begin{tabular}{|c|c|c|c|c|}
\hline p-value & كران بالا & كران هايين & زيرمنحنى سطح & متغير \\
\hline$<0 / 001$ & $\vee \Delta$ & 8) & $8 \Lambda$ & تستوسترون \\
\hline$\%$ & $V_{0}$ & $\Delta \Delta$ & s & نسبت FEV1/FVC \\
\hline$\% \circ 0$ & 99 & $\Delta \mu$ & 4) & كلسترول \\
\hline$\% \Delta Q F$ & \& & FA & $\Delta \wedge$ & فسفر \\
\hline ./lrq & sk & FA & $\Delta \&$ & بيلىروبين كونثروك \\
\hline $0 / 04 t$ & SV & $\omega_{0}$ & Q9 & شمارش گلبول قرمز خون \\
\hline$<0 / 001$ & $v^{\mu}$ & $\Delta \Lambda$ & 90 & هموكلوبين \\
\hline$<0 / 001$ & Vk & Q9 & SV & هماتوكريت \\
\hline
\end{tabular}

در تحليل مميزى كلاسيك، نقاط برش و مقادير حساسيت و ويزگىى

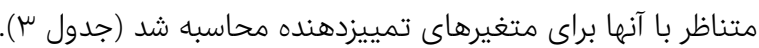

جدول س) نتايج نقاط برش در تحليل مميزى كلاسيك

\begin{tabular}{|c|c|c|c|}
\hline ويزگى (\%) & حساسيت (\%) & نقطه برش & متغير \\
\hline 70 & 77 & $1 . r / \varepsilon 10$ & FEV1/FVC نسبت \\
\hline To & $7 \varepsilon$ & o/omv & تستوسترون \\
\hline $7 \pi$ & $7 \pi$ & $1 \wedge \% / \circ q$ & كلسترول \\
\hline $0 \wedge$ & 70 & $r / 919$ & فسفر \\
\hline$\varepsilon \wedge$ & $7 V$ & $0 / \mu^{\mu} V$ & بيلىروبين كونثوگه \\
\hline 07 & $0 \Lambda$ & $\varepsilon / 97 V$ & شمارش كلبول قرمز خون \\
\hline 07 & س & $10 / .0$ & هموكلوبين \\
\hline س & 70 & $\varepsilon \mu / \mathrm{HO}_{0}$ & هماتوكريت \\
\hline
\end{tabular}

با استفاده از تحليل مميزى كلاسيك و يس از ورود ^ متغير به

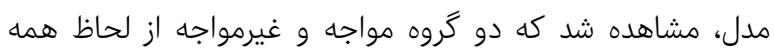

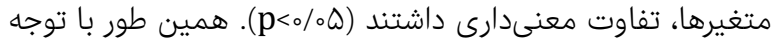

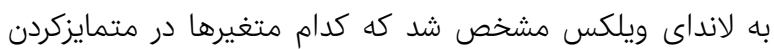

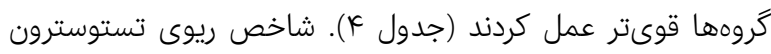

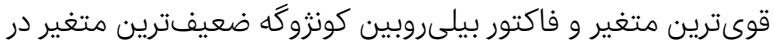

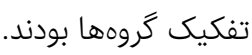

جدول F) معنى Fارى متغيرها و لانداى ويلكس متناظر با آنها

\begin{tabular}{|c|c|c|}
\hline p-value & لانداى ويلكس & متغير \\
\hline$\%$ & ./9VY & FEV1/FVC سببت \\
\hline$<0 / 001$ & o/9MI & نستوسترون \\
\hline$\% \% 7$ & $\circ / 9 \vee \mu$ & كلسترول \\
\hline$\% \mu r$ & 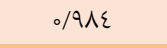 & فسفر \\
\hline$\% \varepsilon \varepsilon$ &.$/ 9 \wedge 7$ & يلىروبين كونزوگه \\
\hline \% & $\circ / 9 \wedge \varepsilon$ & شمارش كلبول قرمز خون \\
\hline$<0 / 001$ & ०/ ૧ & مموكلوبين \\
\hline$<0 / 001$ & ०/quV & هماتوكريت \\
\hline
\end{tabular}

مقدار ضريب همبستكى زيربنايى برابر الهاه و ميزان ارزش ويزه كه

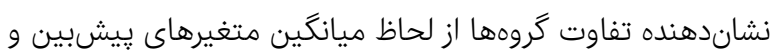

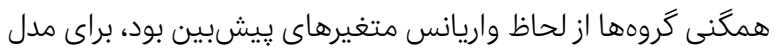


و جزو متغيرهاى تمييزدهنده بود اما به دليل همبستكى بالا با متغير نسبت FEV1/FVC وارد مدل نشد. در مطالعات كذشته در مورد مصدومان شيميايى براى يافتن بيوماركرهاى مهم از روش تحليل مميزى استفاده نشده است، اما درائ

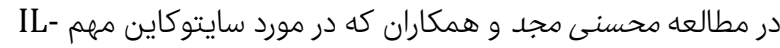
21 در بيمارىهاى التهابى ريوى است، مقادير آن در سرم و خلط، دران،

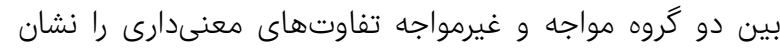

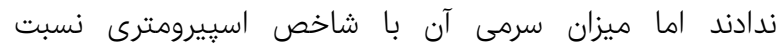

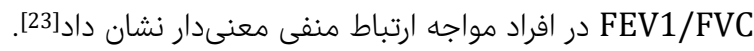

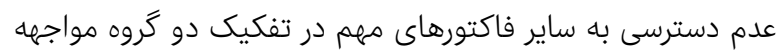

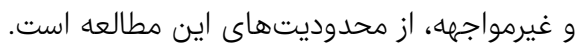

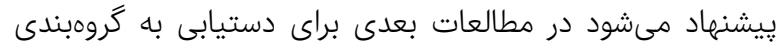

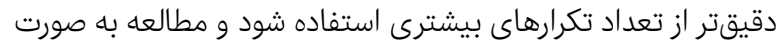
طولى انجام كيرد. همجنين همه فاكتورهاى مهم كمّى و كيفى نيز

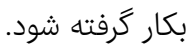

\section{نتيجه گيرى}

در تفكيك مصدومان شيميايى، روشهاى تحليل مميزى كلاسيك

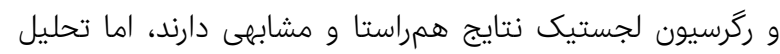
مميزى به دليل ارايه تابع تشخيص، مدل مناسبترى است.

تشكر و قدردانى: برخود لازم مىدانيم از همكارى اعضاى محترم مركز

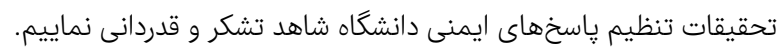

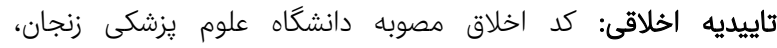

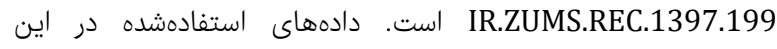

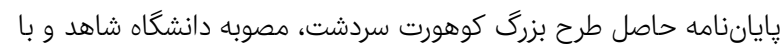

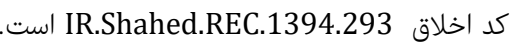
تعارض منافع: اين مقاله مستخرج از پإياننامه كارشناسى ارشد مصوبه

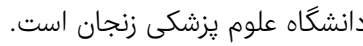

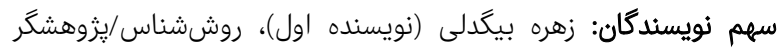

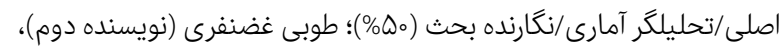

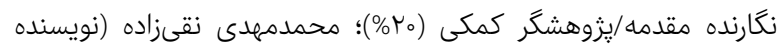

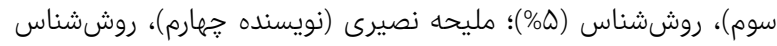

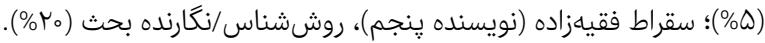

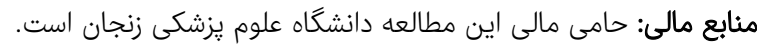

\section{منابع}

1- Belali-Mood M, Hefazi Mehrdad. A Review of the late effects of sulfur mustard gas poisoning. J Birjand Univ Med Sci. 2005;12(3 And 4):9-15. [Persian]

2- Somani S, Babu S. Toxicodynamics of sulfur mustard. Int J Clin Pharmacol Ther Toxicol. 1989;27(9):419-35.

3- Be lali Mood M, Hefazi M. Comparison of early and late toxic effects of sulfur mustard in Iranian veterans. Basic Clin Pharmacol Toxicol. 2006;99(4):273-82.

4- Pauser G, Aloy A, Carvana M, Graninger W, Harrel A, Koller W, et al. Lethal intoxication by wargases on Iranian soldiers. Therapeutic interventions on survivors of

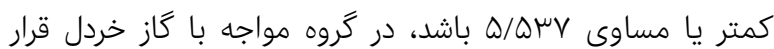

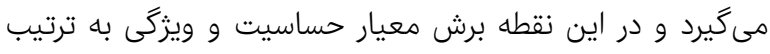

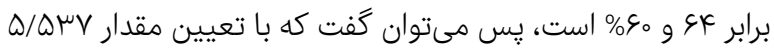

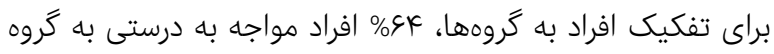
مواجه و همجنين هو\% افراد سالم بهدرستى به كَروه غيرمواجه

تخصيص داده شدند.

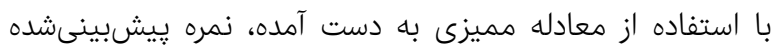

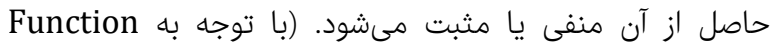

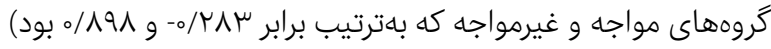

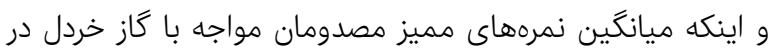

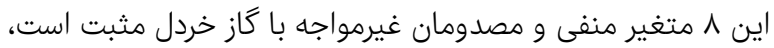

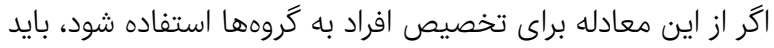

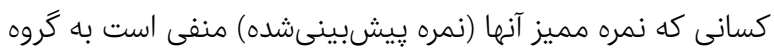
مواج طبقابندى شوند. روش تحليل مميزى كلاسيك و ركرسيون

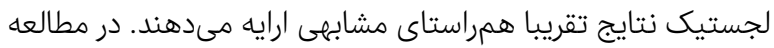

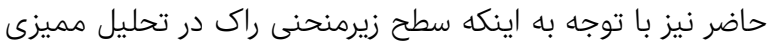

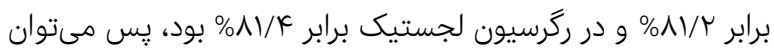

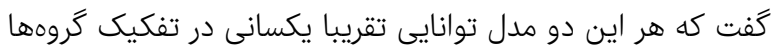

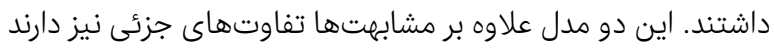

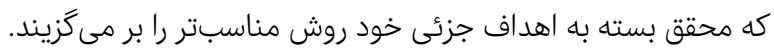

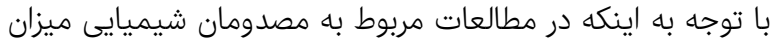

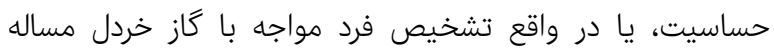

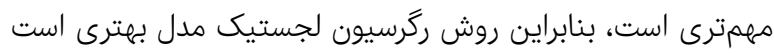

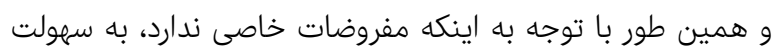

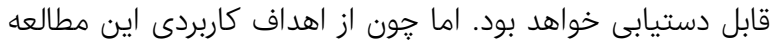

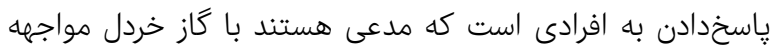
يافتهاند، بنابراين دستيابى به تابع تشخيص امرى ضرى ضرورى است.

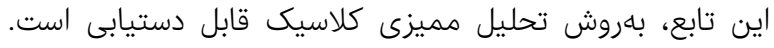
بعضى از مطالعاتى كه در اين زمينه اشتراكاتى با مطالعه حابل حاضر دارند قابل ذكر هستند.

قاهرى و همكاران با استفاده از متغيرهاى كمى و كيفى مرتبط بانيا

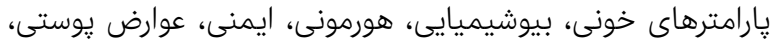

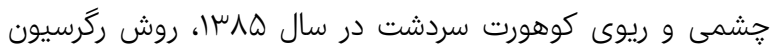

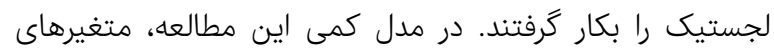

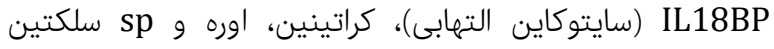

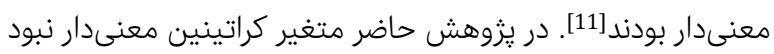
و متغيرهاى كيفى و التهابى حضور نداشتند. در مطالعه كاوماى و همكاران كه مطالعهاى تحليلى-مقطعى براى

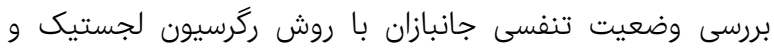

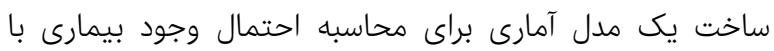

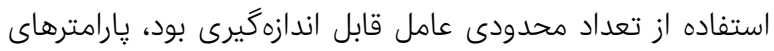

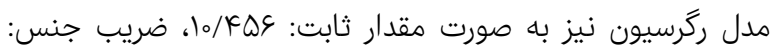

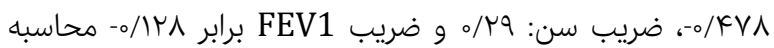
شد [12]؛ در مطالعه حاضر نيز FEV1 در هر دو مقطع معنىدار بوده 
مقايسه تحليل مميزى كلاسيك و ركرسيون لجستيك دو حالتى در تفكيك مصدومان شيميايى ... 190 analyses in evaluating factors associated with asthma prevalence among 10-to 12-years-old children: Divergence and similarity of the two statistical methods. Int J Pediatr. 2009;2009:Article ID 952042.

16- Worth AP, Cronin MTD. The use of discriminant analysis, logistic regression and classification tree analysis in the development of classification models for human health effects. J Mol Struct: THEOCHEM. 2003;622(1-2):97-111.

17- Nasiri M, Faghihzadeh S, Alavi Majd H, Kariman N, Safavi Ardebili N. Longitudinal discriminant analysis with random effects for predicting preeclampsia using hematocrit data. Prev Care Nurs Midwifery J. 2015;4(2):35-44. [Persian]

18- Sedehi M, Mehrabi Y, Kazemnejad A, Hadaegh F. Comparison of artifitial neural network, logistic regression and discriminant analysis methods in prediction of metabolic syndrome. Iran J Endocrynol Metab. 2009;11(6):638-46. [Persian]

19- Press SJ, Wilson S. Choosing between logistic regression and discriminant analysis. J Am Stat Assoc. 1978;73(364):699-705.

20- Balakrishnama S, Ganapathiraju A. Linear discriminant analysis-a brief tutorial [Internet]. Mississippi: Institute for Signal and information Processing; 1998 [Cited 2018 October 1]. Available from: https://www.isip.piconepress.com/publications/reports /1998/isip/lda/lda_theory.pdf

21- AbdolmalekiP, Yarmohammadi M, Gity M. Comparison of logistic regression and neural network models in predicting the outcome of biopsy in breast cancer from MRI findings. Int J Radiat Res. 2004;1(4):217228. [Persian]

22- Makian N, Almodaresi M, Karimi T. Comparison of artificial neural network models with logistic regression and discriminant analysis methods in predict of Companies Bankruptcy. J Econ Res. 2010;10(2):141-61. [Persian]

23- Mohseni Majd A, Ghazanfari T, Dilmaghanian R. Evaluation of serum and sputum level of il-21 in sardasht chemical victims and its relationship with long-term pulmonary complications (27 years after sulfur mustard exposure). Daneshvar Med. 2017;24(129):1-8. [Persian]

mustard gas and mycotoxin immersion. Arch Belg. 1984;341-51.

5- Sohrabpoor H. Observation and clinical manifestation of patient injured with mustard gas. Med J Islamic Rep Iran. 1987;1(1408):32-7.

6-Sega GA, Owens JG, Cumming RB. Studies on DNA repair in early spermatid stages of male mice after in vivo treatment with methyl- , ethyl- , propyl- , and isopropyl methanesulphate. Mutat Res. 1976;36(2):193-212.

7- Klehr NV. Late manifestations in former mustard gas workers with special reference to cutaneous findings. Zeitschrift Hautkrankh. 1984;59(17):1161-4. [Germany] 8- Drasch G, Kretschmer E, Pharm M, Kauert G, Vonmeyer L. Concentration of mustard gas [Bis(2-chloroethylin) sulfide] in the tissues of a vesicant exposure. J Forensic Sci. 1987;32(6):1788-93.

9- Belali Mod M, Hefazi M. The clinical toxicology of sulfur mustard. Arch Iran Med. 2005;8(3):162- 9.

10- Ghazanfari T, Faghihzadeh S, Aragizadeh H, Soroush MR, Yaraee R, Zuhair MH, et al. Sardasht-Iran cohort study of chemical warfare victims: Design and methods. Arch Iran Med. 2009;12(1):5-14. [Persian]

11- Ghaheri A, Faghihzade S, Ghazanfari T, Zayeri F, Sorosh MR. Fitting logistic model to some quantitative and qualitative variables to discriminate between mustard-exposed and non-exposedindividuals. Daneshvar Med. 2011;19(4):9-16. [Persian]

12- Kavei B, Fagihzadeh S, Eskandari F, Kazemnejad A, Gazanfari T, Soroush M. Studying the surrogate validity of respiratory indexes in predicting the respiratory illnesses in wounded people exposed to sulfur mustard. J Arak Uni Med Sci. 2011;13(4):75-82. [Persian]

13- Mousavi B, Soroush MR, Montazeri A. Quality of life in chemical warfare survivors with ophthalmologic injuries: The first results from Iran chemical warfare victims health assessment study. Health Qual Life Outcomes. 2009;7(2):1-6.

14- Aram Ahmadi M, Bahrampour A. Comparison of logistic regression and discriminant analysis in predicting type 2 diabetes. Iran J Epidemiol. 2015;11(3):62-9. [Persian]

15- Antonogeorgos G, Panagiotakos DB, Priftis KN, Tzonou A. Logistic regression and linear discriminant 